\title{
Hidden Constructs on Graduate Employability Decisions: The Principal Component Factor
}

\author{
Anthony Joe Turkson, Cynthia Ama Mensah, Esi Ahema Aboagye \\ Mathematics, Statistics and Actuarial Science Department, Takoradi Technical University, Sekondi-Takoradi, Ghana \\ Email: anthony.turkson@ttu.edu.gh
}

How to cite this paper: Turkson, A.J., Mensah, C.A. and Aboagye, E.A. (2021) Hidden Constructs on Graduate Employability Decisions: The Principal Component Factor. Open Journal of Statistics, 11, 720-736. https://doi.org/10.4236/ojs.2021.115043

Received: August 24, 2021

Accepted: October 9, 2021

Published: October 12, 2021

Copyright $\odot 2021$ by author(s) and Scientific Research Publishing Inc. This work is licensed under the Creative Commons Attribution International License (CC BY 4.0).

http://creativecommons.org/licenses/by/4.0/

\begin{abstract}
This study adopted the quantitative research design to unearth hidden factors which go into graduate employability decisions. Purposive sampling technique was used to select graduates, institutions and industries within Takoradi, Cape Coast, Kumasi and Accra metropolis all in Ghana. Three different questionnaires inter-spaced with interviews were designed and used to collect data from the field according to a pre-determined stratified scheme. A total of 200 informants including 68 industries, 120 graduates and 12 institutions were used. The data was coded and keyed into SPSS version 20. Tables and Charts were used to explore the data. Principal component (PC) analysis was employed to extract hidden factors industries consider in graduate employability decisions. The PC method identified and extracted six hidden factors: ability to set SMART goals and structure actions; ability to demonstrate a willingness to embrace new systems, processes, technology and ideas; a determined, committed, resilient, and focused person; a person with passion for driving profit; ability to deconstruct a problem or situation; and clear and unprompted ability to present information to a group. These six hidden factors could explain $68.8 \%$ of the variances in graduate employability decisions. We recommend that internships be properly planned and executed with the involvement of industry players, facilitators of learning, and the ministry of trade and industries. In addition, facilitators should inculcate into students' important traits and attributes identified in this study.
\end{abstract}

\section{Keywords}

Competency-Based Training, Graduate Employability Decisions, Internships, Principal Component Analysis, Sustainable Employments

\section{Introduction}

Employability denotes skills and attributes that make an individual acceptable to 
potential employers. For the past ten years, the nation has witnessed a tremendous increase in the number of higher education institutions (HEIs): public and private universities, polytechnics and other colleges of higher learning. The major feature of these institutions is that all of them churn out thousands of graduates each year into the job market with various levels of expertise. A diploma or degree is no longer a guarantee of employment. The economy, relatively small offers limited number of job opportunities, and the imbalance between the supply of graduates and the number of job vacancies in the market workforce calls for concerns. These concerns are enough motivation for driving these institutions into developing programmes meant to equip their graduates with knowledge and skills necessary to enhance their employability opportunities. As a consequence, the relationship between knowledge and skills possessed by graduates and demand of employers has been the subject of intensive empirical research.

According to reference [1], if there is any hope of transferring the learning skills from one source to the other, then, the learner will be exposed to a variety of different learning situations. It seems to us that the adage that practice makes one perfect applies to employability too. Researchers have noted that practice in a number of contexts was fundamental to the development of employability skills and attributes. The essence of establishing higher education institutions (HEIs) such as polytechnics and universities is to equip students with the necessary competencies which will provide employability skills for the teeming youth in Ghana, with the view of curbing unemployment and alleviating poverty. To benefit from such education, stakeholders ought to ensure that institutions' curricula are focused and blended with the needs of industry and thus make it acceptable by society. Bridging the gap between the institutions' curricula and industry needs has been the concern of governments and other stakeholders from the dawn of time till date. Studies have shown a number of factors which contribute towards graduate inability to secure jobs after school-the factors include poor performance of graduates at work places, lack of knowledge and skills required by industry and attitude to work. The questions we need to ask ourselves are as follows: Are the content of instructions of our HEIs in consonance with the skills and competencies required by the industries? Do the graduates of these HEIs have the requisite knowledge and employability skills to easily slide into the changing needs of industries? Concerns have been raised worldwide that the existing undergraduate programmes were not producing graduates with the kind of lifelong learning skills and professional skills which they needed in order to be successful in their careers. Reference [2] has opined that being in possession of employer-relevant knowledge, skills and attitudes were not enough for an individual to be relevant within the labour market, and to realise their potential, they need to explore their assets and market them. Reference [3] has presented two main concepts of employability: the educational concept relating to the ability of graduates to handle graduate jobs; and the ability of graduates to get a job. This appears to be the first concept which most practitioners in HEIs are primarily 
concerned with.

This study is an attempt to draw together the various concepts of employability with respect to Higher Education (HE) globally. Though this study area is a rapidly growing area for research, we do not hope to comprehensively cover all aspects of employability; nonetheless, this study aims at putting the main issues into context. The motivation behind this study is hinged on using scientifically proven methods to unearth the hidden factors that go into graduate employability decisions. Over the years, graduate unemployment has been on the rise, many attempts by governments and other stakeholders to nip this canker into the bud has proven futile. Through this work, institutional curricula reforms could be made in line with industry needs.

The study was delimited to Takoradi, Cape Coast, Accra and Kumasi metropolis. It was also delimited to a sample size of 200 comprising of 120 graduates, 68 industries and 12 higher educational institutions. Furthermore, the study was delimited to the use of the purposive sampling technique.

\subsection{Conceptual Framework}

Different streams of literature have defined the concept of employability differently but related. This research takes an interdisciplinary approach to analyzing the problem at hand, it combines insights from research on higher education and workplace learning; in doing so, we took a multi-dimensional, competence-based approach. Our approach to conceptualizing employability is in response to research outputs from both disciplines-higher education and workplace learning-which argue for a need for integrating both approaches to employability to achieve a unified overview of conceptual frameworks and agreement on definitions of the concept. In our globally competitive knowledge economy, where change is an everyday reality, the importance of employability is generally agreed-upon by policy makers and scholars alike [4]. According to reference [5], higher education institutions need to prepare students for jobs that do not yet exist, prepare them for using technologies that have not yet been invented, and for solving problems that nobody has yet thought of. Reference [6] has noted that once graduates are part of the labor market, they need to continue working on their employability in order to find and keep jobs. Hence, economic, political and social pressures should compel policy makers and higher education professionals to prioritize the topic of employability in strategic agendas.

Reference [4] has underscored the fact that most research attention was focused on personal resources, probably because these were tied to the individual and generally more easily adaptable while the context was often beyond the individual's control. They developed a conceptual framework that integrated the various facets of employability decisions and found two types of distinctions: An employability distinction, which differentiated between job-related, career-related, and development-related employability, and a capital distinction, which differentiated between human capital (more specifically knowledge, skills, and attitudes) and social capital. They performed a Q-sorting study in which items of 
existing measurements were mapped onto the conceptual framework by subject matter experts. Overall, they found support for the conceptual framework. They asserted that employability was important since it maximizes an individual's likelihood of attaining personal goals, ambitions, and aspirations. Their work was based on the works done by researchers like [7]; [8] and reduced the threat of job loss and the negative consequences associated with job insecurity which was first underscored by [9]. These benefits associated with employability have stimulated researchers to examine both personal and contextual factors that can promote individuals' employability. Their study focus was on personal resources which promoted individual's employability. They introduced the notion of "employability capital" which was a variation on the term "movement capital", which had been used in earlier researches. They averred that the use of movement capital focused on one feature of employability, that is, the likelihood to find a new job, does not adequately capture the second employability feature-which is the likelihood to keep a job. Accordingly, the term employability capital was found to be more accurate to capture the combination of obtaining and retaining employment.

Reference [10] has noted that an extensive study had been done on employability and the factors that led to employability. They noted that previous studies had focused on career development, internships, work experience, soft-skill development, and even university admission criteria which could be considered external factors to university student learning experience. They indicated that focus on these external factors and their influence on employability appeared to have taken attention away from the core function of university education which was "learning". They averred that learning done in universities has been the focus of many studies but it was difficult to find a consensus due to different learning models and approaches considered. It was revealed that learning and employability were clearly supportive constructs but that this relationship appeared to be under represented and lacked clarity. They presented a new study scheme to overcome the issue by introducing a framework that clearly represented learning and employability in a manner that was both easy to understand and at the same time provided necessary theoretical support. The "learning and employability framework" that was presented was an attempt to overcome the limitations of popular employability models which either lacked operational clarity or simplicity. The model identified new dimensions of employability which were not considered in previous studies and linked learning process, learning environment and learning outcomes to employability. Previous studies revealed these outcomes: University reputation and learning outcomes and their influence on graduate employability. It was concluded that while learning outcomes appear to mediate the relationship between lower-tier employability skills and employability, the university's reputation appears to moderate learning outcome and employability. It was again noted that the "learning and employability framework" could be considered as a timely and relevant study because it was simple enough to be understood by students, parents, employers and faculty while providing the 
required operational clarity and theoretical support for research community. The framework provides direction to those looking to design curricula and pedagogic approach to maximize employability.

Reference [11] has conducted a study that provided a conceptual framework for understanding what employers thought about on the value of graduates with similar educational credentials in the workplace (their employability). Their study made use of insights from the new institutionalism. In their study framework, employers' beliefs about graduates' employability were broken into a number of factors and mechanisms, including exogenous factors, initial signaling effects and the processes of both private and public learning. With such conceptualization, they discussed the implications for international higher education providers on how to improve their graduates' employment by influencing employers' beliefs.

\subsection{Operational Definition of Employability}

In simple terms, employability is about being capable of getting and keeping fulfilling work. More comprehensively employability is the capability to move self-sufficiently within the labour market to realize potential through sustainable employment. For the individual, employability depends on the knowledge, skills and attitudes they possess, the way they use those assets and present them to employers and the context [2].

Reference [12] alluded to the fact that if the notion of employability is to contribute to the quality of higher education, then it is rather important to disentangle competing preconceptions about what it is, how it might be measured and how it must be promoted. He averred that individual "Employability" is infrequently explicitly and clearly defined. He pointed out that there were several definitions implicit in the literature, and stated that in all cases the core notion related to the propensity of students to obtain a job. He presented five key operational definitions or questions bothering on employability with explicit and implicit elaboration on this core notion either in all or in any of the following:

\subsubsection{Job Type}

For some, employability is about securing any job, given that there is a view that it is no longer possible to delimit a graduate job. For others, it implies getting a graduate-level job which may be referred to as fulfilling work, or as a job that requires graduate skills and abilities or as a career-oriented job.

\subsubsection{Timing}

The question he asked was "Is employability signalled by getting a job within a specified time after graduating, or by getting a job before any need for retraining"?

\subsubsection{Attributes on Recruitment}

Does employability signify an ability to demonstrate desired attributes at the point of recruitment, to "hit the deck running"? or, alternatively, is it develop- 
mental, indicating the likely ability to develop attributes, "to get up to speed quickly"?

\subsubsection{Further Learning}

One view of employability holds that" the degree is not the end of learning" and values graduates who are ready for further development, while another places more weight on achievement at graduation, while recognizing the importance of "willingness to learn and continue learning".

\subsubsection{Employability Skills}

Employability can be understood as the possession of basic "core-skills", or an extended set of generic attributes, or attributes that a type of employer (discipline-linked, sector-related, company-type) specifies. Sometimes they get specified in detail or, more often, shorthand key skills.

\subsection{Employability Skills}

Reference [13] has defined employability skills in terms of four key areas: traditional intellectual skills (e.g., critical evaluations and logical argument); key skills (e.g., communication and information technology); personal attributes (e.g., motivation and self-reliance) and knowledge of organization and their functions. Reference [12] has noted that employability is not just about getting a job; it is about developing attributes, techniques or experiences just to enable a graduate to get a job, or to progress within a current career. He further noted that employability was all about learning and called on HEIs to place less emphasis on "employ" and more emphasis on "ability". Reference [2] carried out a study on developing a framework for policy analysis on employability. Their main findings were that "Employability is all about having the capability to gain initial employment, maintain employment and obtain new employment if required".

They concluded that for the graduate, employability depended on:

- Acquisition of assets in terms of knowledge, skills and attitudes;

- Usage and deployment of assets;

- Presentation of assets to potential employers; and

- The context within which the individual works, e.g., labour market, personal circumstances.

\subsection{Industries' Concept on Employability}

Researchers have observed that businesses want graduates who can read, write, speak intelligently, solve problems, work collaboratively, understand mathematics and science, possess a good work ethic and professional attitude, understand self-theories that are marked by confidence, optimistic, believe that they can make a difference, can adapt to the workplace culture, can use their abilities and skills to evolve the organization, value critical thinking, bring about innovations, be leaders of change and can participate in teamwork [14] [15] [16] [17] [18]. Over the years, industries tend to complain about the abysmal performance of 
graduates they employed and the accompanying problem of having to spend a lot of resources in retraining them to become fit-for-purpose. Reference [19] has observed that only a minority of students who gain employment directly utilised the academic content of their degree programme. Reference [20] also noted that Industries' criticism of the shortcomings of graduate was not so much the results of failure in the higher education curriculum, rather of failure in the transfer process. He sees transfer as a learning process in its own right. Reference [21] has added his voice to the importance of transferable key skills to employment contexts. Reference [22] believes that learning and the transfer of that learning is most likely to be effective if the learning situation closely resembles the work place situation. The process of this learning transfer may include internships for student, practical work through the use of modern technology and equipment and the use of everyday life issues in teaching.

References [3] [12] and [23] have alluded to the fact that on an increasing basis, graduate attributes were becoming more and more important than the programme or subject they studied. For some employers, the subject studied was not as important as the graduates' ability to handle complex information and communicate it effectively. Graduate recruiters want a variety of other skills, personal and intellectual attributes, rather than specialist subject knowledge, oral communication, teamwork, self-management, problem solving, and leadership.

\section{Material and Methods}

\subsection{Research Design}

The study adopted the quantitative research design. The population of interest was graduates, industries and higher educational institutions within the Takoradi, Cape Coast, Kumasi and Accra metropolis. These cities were selected because they had enough industries, institutions and churns out lots of graduates annually. The industries enlisted ranged from manufacturing, production, and services. The higher education institutions selected were universities, polytechnics and other higher educational institutions.

\subsection{Source of Data}

Primary source of data was used by the investigators for the study. The data was obtained directly from the informants who were stratified according to the pre-defined sampling units. The information was obtained via Interviews, surveys, and fieldwork. These sources were used because it provided direct evidence concerning a topic under study; moreover, it is more exact and presents information in its original form.

\subsection{Research Instruments}

Both closed-ended and open-ended questionnaires were designed and used for the study. It was inter-spaced with interviews. Three different questionnaires were used in gathering the data. The first questionnaire was used to collect data 
from graduates. The second was used to get data from the industry regarding preferred graduate employability needs. The third was used to collect data on the curricula of HEIs. The questionnaires were self-administered with the help of trained enumerators.

\subsection{Sampling Technique}

Purposive sampling technique was used for the study. This method is useful when research units in the population are very few and likely to be missed in the selection process when other methods are employed. The method was used to select units for the sample that were considered representative of the population. Graduates were divided into polytechnics, universities and other higher education institutions (both private and public). For the industries, the following were considered: manufacturing, mining, and services. From these groupings the required number of sampling units was selected. A total of 200 sampling units were used; this is made up of 68 industries, 120 graduates and 12 HEIs.

\subsection{Data Analysis}

The data was combed, coded and keyed into SPSS version 20. Pie charts and tables were used to explore the data. Principal component analysis (PCA) was employed to do further analysis. This was done to unearth the hidden factors that industries consider in graduate employability decisions. A brief description of the principles governing PCA is discussed below

\subsubsection{Principal Component Analysis (PCA)}

Principal component analysis is a statistical technique that is used to analyze the interrelationships among a large number of variables and to explain these variables in terms of a smaller number of variables, called principal components (PC), with a minimum loss of information. Often the variables under study are highly correlated and as such are effectively "saying the same thing". It may be useful to transform the original set of variables to a new set of uncorrelated variables called principal components. These new variables are linear combinations of the original variables and are derived in decreasing order of importance so that the first PC accounts for as much as possible of the variation in the data, the second PC accounts for maximum variance that was not accounted for by the first PC and so on [24]. We need an inter-variable correlation $>0.30$ otherwise the PCA would not accomplish much, large inter-variable correlations do not guarantee a solution either, while two variables may be highly correlated, they may not be correlated with each other. Kaiser's measure of sampling adequacy can help assess the inter-variable correlations. If the Kaiser's ratio approaches 1 then the inter-variable correlations are small.

\subsubsection{Models of Principal Components}

We could let $X=\left[x_{i}\right]$ be any $k \times 1$ random vector and define a $k \times 1$ vector $Y=$ $\left[y_{i}\right]$, where for each $i$ the $i$ th principal component of $X$ is 


$$
y_{i}=\sum_{j=1}^{k} B_{i j} x_{j}
$$

for some regression coefficients $\beta_{i j}$. Since each $y_{i}$ is a linear combination of the $x_{j}$, $Y$ is a random Vector. Now define the $k \times k$ coefficient matrix $\beta=\left[\beta_{i j}\right]$ whose rows are the $1 \times k$ vectors $\beta^{\mathrm{T}} X=\left[\beta_{i j}\right]$. Thus,

$$
y_{i}=\beta^{\mathrm{T}} X, \quad Y=\beta^{\mathrm{T}} X
$$

For reasons that will become apparent shortly, we choose to view the rows of $\beta$ as column vectors $\beta_{i}$ and so the rows themselves are the transpose of $\beta^{\mathrm{T}} X$.

Observation: Let $\Sigma=\left[\sigma_{i j}\right]$ be the $k \times k$ population covariance matrix for $X$. Then the covariance matrix for $Y$ is given by $\Sigma_{Y}=\beta^{\mathrm{T}} \Sigma \beta$, i.e., population variances and covariance of the $y_{i}$ are given by [25]

$$
\operatorname{var}\left(y_{i}\right)=\sum_{p=1}^{k} \sum_{m=1}^{k} \beta_{i p} \beta_{i m} \sigma_{p m}=\beta_{i}^{\mathrm{T}} \Sigma \beta_{i} \operatorname{cov}\left(y_{i}, y_{j}\right)=\sum_{p=1}^{k} \sum_{m=1}^{k} \beta_{i p} \beta_{j m} \sigma_{p m}=\beta_{i}^{\mathrm{T}} \Sigma \beta_{j}
$$

\subsubsection{Scree Plot of Eigenvalues}

Another way to determine how many factors should be kept in the remainder of the analysis is to use the scree plot. The scree plot simply displays the eigenvalues for each of the factors in a plot, from the first eigenvalue (the one that explains the most variance) to the last eigenvalue [26].

\section{Results}

\section{Reliability of the Instrument}

Table 1 gives the KMO, Bartlett's Test and Reliability statistic for the questionnaire. Cronbach's alpha reliability test [which ranges from 0 to 1 ] was used to ensure reliability of the research instrument. A value closer to 1 indicates greater reliability and consistency. The value of Cronbach's alpha (0.701) which falls within the acceptable region indicates that the research instrument is consistent and reliable. The KMO measure of sampling adequacy and that of the Bartlett's test which assess whether or not the correlation matrix was suitable for factor analysis is also shown in the same table. Both the KMO value of 0.514 (which is closer to the minimum threshold of 0.60 and the Bartlett's test ( $p$ value $=0.025$ ) suggest that the sample size was adequate and that, at least, some of the variables were inter-correlated and therefore the data was suitable for factor analysis.

The communalities have been shown in Table 2. In PCA, all variables are assigned an initial variance (total communality). The final communalities of each variable represent the variance accounted for by the chosen factor solution of the variable. All the variables used in the analysis remained in the final factor solution, they all remained because their communalities were greater than 0.50 . This means that at least $50 \%$ of the initial communality of each variable was accounted for in the final factor solution. The factor solution is thus considered to be satisfactory since at least half of the variance of each variable is shared with 
Table 1. KMO, Bartlett's Test and Reliability statistics.

\begin{tabular}{ccc}
\hline \multicolumn{2}{c}{ Kaiser-Meyer-Olkin Measure of Sampling Adequacy. } & 0.514 \\
Bartlett's & Approx. Chi-Square & 75.380 \\
Test of Sphericity & $\mathrm{df}$ & 66 \\
Cronbach's Alpha & Sig. & 0.025 \\
Cronbach's Alpha & Cronbach's Alpha Based on Standardized Items & Number of Items \\
0.701 & 0.707 & 12 \\
\hline
\end{tabular}

Table 2. Communalities of the data.

\begin{tabular}{ccc}
\hline & Initial & Extraction \\
\hline Verbal communication & 1.000 & 0.773 \\
team work & 1.000 & 0.635 \\
commercial awareness & 1.000 & 0.802 \\
Analysis and investigation & 1.000 & 0.808 \\
initiative or self-motivation & 1.000 & 0.661 \\
drive & 1.000 & 0.760 \\
written communication & 1.000 & 0.754 \\
planning and organizing & 1.000 & 0.509 \\
flexibility & 1.000 & 0.657 \\
time management & 1.000 & 0.632 \\
transferable skills & 1.000 & 0.511 \\
personal skills or competences & 1.000 & 0.751 \\
\hline
\end{tabular}

the factors (Table 4 and Table 5).

Table 6 and Table 7 shows that 6 components were extracted. These factors could cumulatively explain $68.8 \%$ of the variability in the original data which is higher than the minimum threshold of $60 \%$.

\section{Discussion}

The result reveals that $52(76.5 \%)$ of the 68 industries were from the private sector while 16 (23.5\%) were from the public sector. From Table 3, 16 (23.5\%) of the industries were into banking services, 7 (10.3\%) were into life insurance services, 13 (19.1\%) were into shipping and logistics, 10 (14.7\%) were into automobile services, 12 (17.6\%) run healthcare services and 10 (14.7\%) were into oil and gas businesses.

The attributes that industries look out for in selecting graduates for employment is shown in Table 4. These attributes have been listed in decreasing order of importance: adherence to work ethics (100\%), having initiative and being innovative (100\%), work experience/internships/placements (98.5\%), trustworthiness (94.1\%), expertise in the field of study (92.6\%), commitment (89.7\%), 
Table 3. Nature of the business of the industries.

\begin{tabular}{cccc}
\hline & Frequency & Percent & Cumulative Percent \\
\hline Banking services & 16 & 23.5 & 23.5 \\
(including savings and loans services) & 7 & 10.3 & 33.8 \\
Life Insurance & 13 & 19.1 & 52.9 \\
Shipping and Logistics & 10 & 14.7 & 67.6 \\
Automobile services & 12 & 17.6 & 85.3 \\
Healthcare services & 10 & 14.7 & 100.0 \\
Oil and Gas & 68 & 100.0 & \\
Total & &
\end{tabular}

Table 4. Attributes industries consider for graduate employment.

\begin{tabular}{|c|c|c|}
\hline Attributes & $\begin{array}{c}\text { Yes } \\
\%\end{array}$ & $\begin{array}{c}\text { No } \\
\%\end{array}$ \\
\hline Work experience/internships/placement & 98.5 & 1.5 \\
\hline Attitude/behaviour/disposition/Stature & 10.3 & 89.7 \\
\hline Adherence to work ethics & 100.0 & 0.0 \\
\hline Gender & 13.2 & 86.8 \\
\hline Programme of study & 85.3 & 14.7 \\
\hline Division (class) of student & 8.8 & 91.2 \\
\hline Performance at interview & 82.4 & 17.6 \\
\hline Expertise in the fieldwork & 92.6 & 7.4 \\
\hline Engaging in extra-curricular activities & 2.9 & 97.1 \\
\hline Professional association member/engagement & 5.9 & 94.1 \\
\hline Personal development/Appearance & 66.2 & 33.8 \\
\hline Parental background & 0.0 & 100.0 \\
\hline Religious background & 0.0 & 100 \\
\hline Collaboration and cooperation & 70.6 & 29.4 \\
\hline Organizational ability & 14.7 & 85.3 \\
\hline Time management & 57.4 & 42.6 \\
\hline Political affiliation & 0.0 & 100.0 \\
\hline Ethnic background & 0.0 & 100.0 \\
\hline Empathy & 30.6 & 69.4 \\
\hline Adaptability & 85.3 & 14.7 \\
\hline Having initiative/Innovation & 100.0 & 0.0 \\
\hline Self-control & 77.9 & 22.1 \\
\hline Trustworthiness & 94.1 & 5.9 \\
\hline Conscientiousness & 30.9 & 69.1 \\
\hline Achievement driven & 80.9 & 19.3 \\
\hline Being committed & 89.7 & 10.3 \\
\hline A person interested in details & 77.9 & 22.1 \\
\hline Being optimistic & 54.6 & 45.4 \\
\hline Having influence & 23.5 & 76.5 \\
\hline
\end{tabular}


nature of programme of study (85.3\%), adaptability (85.3\%), performance at interview (82.4\%), achievement driven(80.9\%), self-control (77.9\%), a person interested in details $(77.9 \%)$, collaboration and cooperation (70.6\%), personal development and appearance(66.2\%) time management (57.4\%) and optimistic (54.6\%).

Table 5 gives us data on the skills for employability decisions. The key skills that most industries expect from graduates include but not limited to the following: flexibility (100\%), personal competence (98.5\%), verbal/written communication (97.1\%), planning and organisation (97.1\%), initiative and self-motivation

Table 5. Skills industries value during graduate recruitment.

\begin{tabular}{|c|c|c|}
\hline Skills & $\begin{array}{c}\text { Yes } \\
\%\end{array}$ & $\begin{array}{c}\text { No } \\
\%\end{array}$ \\
\hline IT/ICT skills & 86.9 & 13.1 \\
\hline Team work skills & 67.6 & 32.4 \\
\hline Conflict management skills & 10.3 & 89.7 \\
\hline Entrepreneurial skills & 60.0 & 40.0 \\
\hline Persuasion and negotiation skills & 88.5 & 11.5 \\
\hline Computer application skills (office, word, excel, powerpoint) & 75.0 & 25.0 \\
\hline Statistical skills/Computational skills & 23.5 & 76.5 \\
\hline Business communication skills & 83.8 & 16.2 \\
\hline Flexibility skills & 100 & 0.0 \\
\hline Financial management skills & 5.9 & 94.1 \\
\hline Planning and organization & 97.1 & 2.9 \\
\hline Building rapport skills & 85.0 & 15.0 \\
\hline Social or interpersonal skills & 67.2 & 32.8 \\
\hline Research ability & 50.0 & 50.0 \\
\hline Reasoning skills & 70.6 & 29.4 \\
\hline Problem identification and solving skills & 83.8 & 16.2 \\
\hline Advocacy skills & 29.4 & 70.6 \\
\hline Presentation skills & 83.8 & 16.2 \\
\hline Leadership skills & 66.2 & 33.8 \\
\hline Creative thinking skills & 86.8 & 13.2 \\
\hline Initiative and self-motivation skills & 97.0 & 3.0 \\
\hline Analysis and Investigation & 52.9 & 47.1 \\
\hline Verbal and written communication skills & 97.1 & 2.9 \\
\hline Decision making skills & 86.8 & 13.2 \\
\hline Personal Competence & 98.5 & 1.5 \\
\hline Motivational skills & 14.7 & 85.3 \\
\hline Drive & 96.1 & 3.9 \\
\hline
\end{tabular}


(97\%), drive (96.1\%), problem-solving (89.7\%), persuasion and negotiation (88.2\%), IT/ICT (86.9\%), decision making (86.8\%), creative thinking $(86.8 \%)$, building rapport $(85.0 \%)$, problem identification and solving $(83.8 \%)$, presentation (83.8\%), initiative (80.9\%), computer application (office, word, excel, power point) $(75 \%)$, reasoning $(70.6 \%)$, team work (67.7\%), leadership (66.2\%), entrepreneurial (60\%), analysis and investigation(52.9\%), and research ability (50\%).

The pie chart in Figure 1 shows the views of industries concerning graduate employability. $42.7 \%$ of them said there was a gap between what goes on in industry and what goes on in the classroom, 25\% were of the view that graduates do not have the skills and attributes that the industries needed, only $4.4 \%$ say that graduates have the skills and attributes that industries needed, interestingly, 27.9\% abstained from saying anything about graduate employability. From the foregoing results, majority of industries (78\%) pointed out that there was a gap between what goes on in the classroom and industry. Moreover, graduates lacked the skills needed for them to slide easily into the world of work. What this means is that to secure a job in this competitive job market, the learning institutions, graduates and the industries have a serious role to play to ensure that graduates were well prepared for the world of work.

The results of the PCA threw more light on the latent constructs (attributes and skills) that could be used to access graduate employability. The scree plot assisted us to extract six components that have a telling effect on graduate employability decisions. The eigenvalue less than one concept also revealed six constructs that have a very strong influence on graduate employability. After assessing all the 12 factors that could possibly contribute towards graduate employability (Table 2) only 6 came out as the rotated principal components (Table 6 and Table 7) which could boost the employability skills or attributes that most organizations look forward to in graduates, these components together with their factor loadings and total variance explained are provided as follows:

Anything you want to tell us about graduate employability

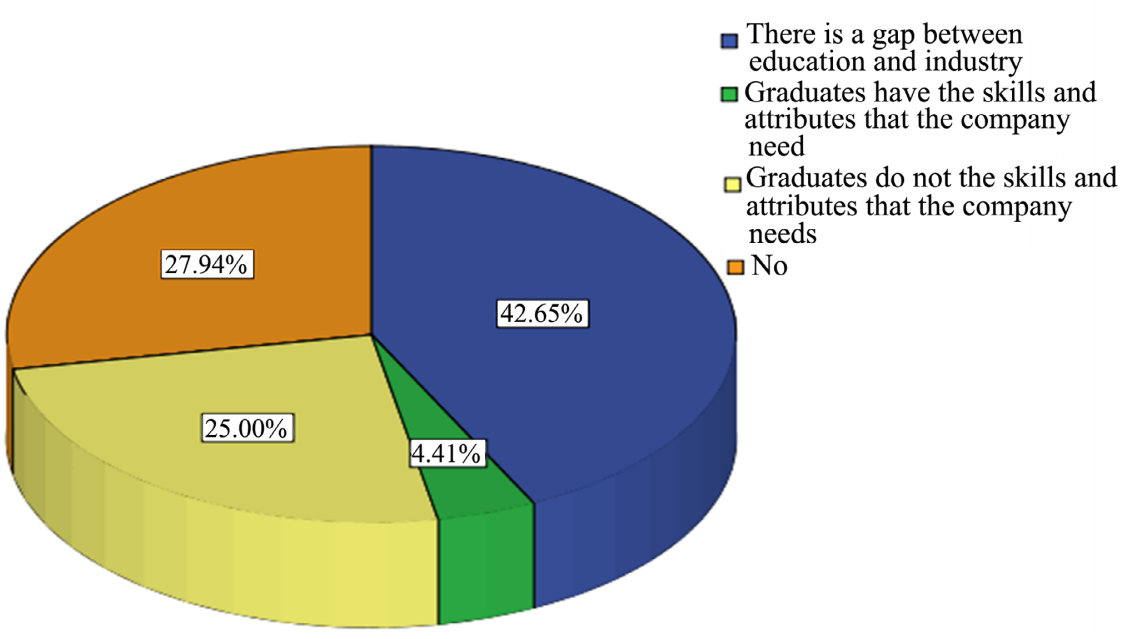

Figure 1. Views of industries about graduate employment. 
Table 6. Results from principal component analysis showing total variance explained.

\begin{tabular}{|c|c|c|c|c|c|c|c|c|c|}
\hline \multirow{2}{*}{ Comp } & \multicolumn{3}{|c|}{ Initial Eigenvalues } & \multicolumn{3}{|c|}{$\begin{array}{c}\text { Extraction Sums } \\
\text { of Squared Loadings }\end{array}$} & \multicolumn{3}{|c|}{$\begin{array}{c}\text { Rotation Sums } \\
\text { of Squared Loadings }\end{array}$} \\
\hline & Total & $\begin{array}{l}\% \text { of } \\
\text { Var }\end{array}$ & $\begin{array}{c}\text { Cum } \\
\%\end{array}$ & Total & $\begin{array}{l}\% \text { of } \\
\text { Var }\end{array}$ & $\begin{array}{c}\text { Cum } \\
\%\end{array}$ & Total & $\begin{array}{l}\% \text { of } \\
\text { Var }\end{array}$ & $\begin{array}{c}\text { Cum } \\
\%\end{array}$ \\
\hline 1 & 1.936 & 16.134 & 16.134 & 1.936 & 16.134 & 16.134 & 1.729 & 14.404 & 14.404 \\
\hline 2 & 1.566 & 13.048 & 29.182 & 1.566 & 13.048 & 29.182 & 1.425 & 11.875 & 26.279 \\
\hline 3 & 1.443 & 12.028 & 41.210 & 1.443 & 12.028 & 41.210 & 1.321 & 11.005 & 37.284 \\
\hline 4 & 1.210 & 10.083 & 51.293 & 1.210 & 10.083 & 51.293 & 1.278 & 10.654 & 47.938 \\
\hline 5 & 1.086 & 9.054 & 60.347 & 1.086 & 9.054 & 60.347 & 1.258 & 10.487 & 58.425 \\
\hline 6 & 1.011 & 8.422 & 68.768 & 1.011 & 8.422 & 68.768 & 1.241 & 10.344 & 68.768 \\
\hline 7 & 0.841 & 7.005 & 75.774 & & & & & & \\
\hline 8 & 0.737 & 6.142 & 81.915 & & & & & & \\
\hline 9 & 0.655 & 5.458 & 87.373 & & & & & & \\
\hline 10 & 0.586 & 4.884 & 92.257 & & & & & & \\
\hline 11 & 0.490 & 4.085 & 96.342 & & & & & & \\
\hline 12 & 0.439 & 3.658 & $1.000 \mathrm{E} 2$ & & & & & & \\
\hline
\end{tabular}

NB: comp = component var = variance Cum = cumulative.

Table 7. Principal component analysis results showing rotated component matrices.

\begin{tabular}{|c|c|c|c|c|c|c|}
\hline & \multicolumn{6}{|c|}{ Component } \\
\hline & 1 & 2 & 3 & 4 & 5 & 6 \\
\hline Verbal communication & & & & & & 0.811 \\
\hline \multicolumn{7}{|l|}{ team work } \\
\hline commercial awareness & & & & 0.656 & & \\
\hline analysis and investigation & & & & & 0.885 & \\
\hline initiative or self-motivation & & & & & & -0.544 \\
\hline drive & & & 0.841 & & & \\
\hline written communication & & & & 0.816 & & \\
\hline planning and organizing & 0.647 & & & & & \\
\hline flexibility & & 0.765 & & & & \\
\hline time management & 0.779 & & & & & \\
\hline transferable skills & & & -0.539 & & & \\
\hline personal skills or competences & & 0.616 & & & & \\
\hline
\end{tabular}

The first component; planning with time consciousness could explain the variance by $14.4 \%$, the second component; competences with flexibility (variance explained $=11.9 \%$ ), third component; drive and versatility (variance explained = $11.0 \%$ ), fourth component; commercial knowledge and writing skills (variance explained $=10.7 \%$ ), fifth component; analysis and investigation skills (variance 
Table 8. Summary of skills and attributes that contribute towards graduate employability decisions (ranked in order of importance with 1 being the most important and 6, least important).

\begin{tabular}{|c|c|c|}
\hline & Extracted factors & Hidden factor \\
\hline 1. & Planning with time management & Setting of SMART goals and structuring action. \\
\hline 2. & Competences with flexibility & $\begin{array}{l}\text { Demonstrating a willingness to embrace } \\
\text { new systems, processes, technology, and ideas }\end{array}$ \\
\hline 3. & Drive and versatility & Determined, committed, resilient, focused. \\
\hline 4. & Commercial writing skills & Passion for driving profit. \\
\hline 5. & Analysis and investigation skills & Ability to "deconstruct" a problem or situation \\
\hline 6. & Verbal and initiative skills & $\begin{array}{l}\text { Clear and unprompted ability to present } \\
\text { information to a group }\end{array}$ \\
\hline
\end{tabular}

explained $=10.5 \%$ ), and the sixth component; oral and initiative skills (variance explained $=10.3 \%$ ). All these six hidden components could explain $68.8 \%$ of the variances of the determinants of graduate employability decisions.

\section{Conclusion}

From the outset, we sought to unearth hidden factors that contribute towards graduate employability decisions using primary data from sixty-eight (68) industries, one hundred and twenty (120) graduates and twelve (12) institutions from Takoradi, Accra, Cape Coast and Kumasi. The Principal Component analysis techniques reduced the many skills and attributes to six salient and hidden factors that could be used as determinants for graduate employability decisions. These extracted factors and their hidden constructs are summarized in the table below (Table 8).

\section{Recommendations}

Based on the analysis of this research piece, we make the following recommendations:

1) Internships and industrial attachments should be carefully planned and executed with the involvement of industry players, facilitators of learning and the ministry of trade and industries.

2) Facilitators should inculcate into the learners' skills, knowledge and attributes identified in this study so that they could easily slide into the world of work.

\section{Conflicts of Interest}

The authors declare no conflicts of interest regarding the publication of this paper.

\section{References}

[1] Knight, P.T. and Yorke, M. (2015) Embedding Employability into the Curriculum.

[2] Hillage, J. and Pollard, E. (1998) Employability: Developing a Framework for Policy 
Analysis. Research Brief 85, Department for Education and Employment.

[3] Knight, P.T. and Yorke, M. (2001) Employability through the Curriculum. Tertiary Education and Management, 8, 261-276. https://doi.org/10.1080/13583883.2002.9967084

[4] Peeters, E.J., Nelissen, J., De Cuyper, N., Forrier, A.M., Verbruggen, M. and De Witte, H. (2019) Employability Capital: A Conceptual Framework Tested through Expert Analysis. Journal of Career Development, 46, 79-93. https://doi.org/10.1177/0894845317731865

[5] Kumar, A. (2007) Personal, Academic and Career Development in Higher Education. Soaring to Success. Routledge, London and New York.

[6] Akkermans, J., Brenninkmeijer, V., Huibers, M. and Blonk, R.W.B. (2013) Competencies for the Contemporary Career: Development and Preliminary Validation of the Career Competencies Questionnaire. Journal of Career Development, 40, 245-267. https://doi.org/10.1177/0894845312467501

[7] Rothwell, A. and Arnold, J. (2007) Self-Perceived Employability: Development and Validation of a Scale. Personnel Review, 36, 23-41. https://doi.org/10.1108/00483480710716704

[8] Van der Heijden, B.I., De Lange, A., Demerouti, E. and Van der Heijde, C.M. (2009) Employability and Career Success across the Life-Span. Age Effects on the Employability-Career Success Relationship. Journal of Vocational Behaviour, 74, 156-164. https://doi.org/10.1016/j.jvb.2008.12.009

[9] De Cuyper, N., De Witte, H., Kinnunen, U. and Nätti, J. (2010) The Relationship between Job Insecurity and Employability and Well-Being among Finnish Temporary and Permanent Employees. International Studies of Management \& Organization, 40, 57-73. https://doi.org/10.2753/IMO0020-8825400104

[10] Sumanasiri, E.G.T., Yajid, M.S.A. and Khatibi, A. (2015) Conceptualizing Learning and Employability "Learning and Employability Framework". Journal of Education and Learning, 4, 53-63. https://doi.org/10.5539/jel.v4n2p53

[11] Cai, Y. (2013) Graduate Employability: A Conceptual Framework for Understanding Employers' Perceptions. Higher Education, 65, 457-469. https://doi.org/10.1007/s10734-012-9556-x

[12] Harvey, L. (2001) Defining and Measuring Employability. Quality in Higher Education, 7, 97-109. https://doi.org/10.1080/13538320120059990

[13] Coopers, M. and Lybrand, D. (1998) Skills Development in Higher Education. Report for CVCP/DfEE/HEQE, November, Committee of Vice-Chancellors and Principals of the Universities of the UK (CVCP), London.

[14] Harvey, L. (2000) New Realities: The Relationship between Higher Education and Employment. Tertiary Education and Management, 6, 3-17. https://doi.org/10.1080/13583883.2000.9967007

[15] Wu, S.Y., Zhou, S.Y., Huang, M.X. and Chen, W. (2020) Employment Prospects of Graduates from Sino-Foreign Cooperative Universities in China. Journal of Studies in International Education. https://doi.org/10.1177/1028315320957433

[16] Loon, D. (2017) Education and Innovation Are Keys to Minneapolis Business Success.

https://www.uschamberfoundation.org/blog/post/education-and-innovation-are-ke ys-minneapolis-business-success

[17] Little, B. (2001) Reading between the Lines of Graduate Employment. Quality in Higher Education, 7, 121-129. https://doi.org/10.1080/13538320120060015 
[18] Mattoon, R.H. (2007) Can Higher Education Foster Economic Growth? Proceedings of the Conference Summary, Chicago, 10 June 2007, 1-4.

http://www.blnz.com/news/2008/05/13/higher education foster economic growth a $4662 . \mathrm{html}$

[19] HESA (Higher Education Statistics Agency) (1998) First Destinations of Students Leaving Higher Education Institutions. 1997/98 Edition, HESA Services Ltd., Cheltenham.

[20] Eraut, M. (1994) Developing Professional Knowledge and Competence. Falmer Press, London.

[21] Atkins, M.J. (1999) Oven-Ready and Self-Basting: Taking Stock of Employability Skills. Teaching in Higher Education, 4, 267-280.

https://doi.org/10.1080/1356251990040208

[22] Brown, C.C. (1982) The Effect of the Minimum Wage on Employment and Unemployment. Journal of Economic Literature, 20, 487-528.

[23] Warn, J. and Tranter, P. (2001) Measuring Quality in Higher Education: A Competency Approach. Quality in Higher Education, 7, 191-198.

https://doi.org/10.1080/13538320120098078

[24] Gorsuch, R.L. (1983) Factor Analysis. L. Erlbaum Associates, Hillsdale.

[25] (2017) Real Statistics Using Excel.

https://i1.wp.com/www.real-statistics.com/wp-content/uploads/2013/09/image9168. png

[26] Chartfield, J. and Collins, B. (1990) Factor Analysis for Beginners. Chartfield \& Collins, London. 